\title{
ДИНАМИКА ПОКАЗАТЕЛЕЙ СОСТОЯНИЯ СЕРДЕЧНО-СОСУДИСТОЙ СИСТЕМЫ У ДЕВОЧЕК В ВОЗРАСТЕ 7-10 ЛЕТ В ХУДОЖЕСТВЕННОЙ ГИМНАСТИКЕ
}

\section{DYNAMICS OF INDICATORS OF THE STATE OF THE CARDIOVASCULAR SYSTEM IN GIRLS AGED 7-10 YEARS IN RHYTHMIC GYMNASTICS}

\section{Shuvalova}

Summary: The purpose of this study was to determine the dynamics of indicators of the state of the cardiovascular system in girls aged 7 to 10 years engaged in rhythmic gymnastics. The methods of the study were used to measure blood pressure and heart rate, and methods of mathematical statistics. As a result of the study, we obtained reliable values of changes in the parameters of the cardiovascular system in each of the four examined groups of girls engaged in rhythmic gymnastics. It was revealed that the parameters of heart rate at rest and after exercise, along with blood pressure, are reliable biological markers of physiological changes in the state of the body in young athletes aged 7 to 10 years, undergoing sports training at the initial stage and training stage in rhythmic gymnastics.

Keywords: heart rate, blood pressure, rhythmic gymnastics, adaptation, loads, FSSP.

\author{
Шувалова Лилия Сергеевна \\ Aспирант, ФГБУ «Федеральный научный чентр \\ физической культуры и спорта», Москва \\ lilia9292@mail.ru
}

Аннотация: Цель исследования: Целью данной работы было определить динамику показателей состояния сердечно-сосудистой системы у девочек в возрасте от 7 до 10 лет, занимающихся художественной гимнастикой. В качестве методов исследования использовались измерение артериального давления и частоты сердечных сокращений, методы математической статистики. В результате исследования были полученные достоверные значения изменения показателей сердечно-сосудистой системы в каждой из четырех обследованных групп девочек, занимающихся художественной гимнастикой. Выявлено, что параметры чСС в покое и после нагрузки, наряду с артериальным давлением являются достоверными биологическими маркерами физиологических изменений состояния организма у юных спортсменок в возрасте от 7 до 10 лет, проходящих спортивную подготовку на начальном этапе и тренировочном этапе в художественной гимнастике.

Ключевые слова: ЧСС, АД, художественная гимнастика, адаптация, нагрузки, ФССП.

го мониторинга [7]. Одним из направлений мониторинга состояния ребенка в данном возрасте является контроль показателей сердечно-сосудистой системы. Контроль осуществляется на основе измерения физиологического показателя нормального регулярного синусового ритма, показателя адаптационных возможностей сердечнососудистой системы, а также параметров артериального давления (систолического и диастолического).

\section{Материалы и методы}

В обследовании приняли участие 8о спортсменок в возрасте от семи до десяти лет, проходящих спортивную подготовку на начальном и тренировочном этапе спортивной подготовки. Спортивная подготовка данного контингента осуществляется в Региональной детской общественной организации «Детский молодежный спортивный клуб «ФОРС», Москва. В программу мониторинга состояния сердечно-сосудистой системы включена фиксация показателя нормального регулярного синусового ритма (ЧСС в покое) и показатель адаптационных возможностей сердечно-сосудистой системы и функционального состояния (ЧСС после 30 приседаний). Зафиксированы усредненные значения данных показателей 
для каждой из четырех возрастных групп. Зафиксированы показатели систолического давления (силы, с которой насыщенная кислородом кровь выталкивается из сердца и расходится по телу) в покое сидя, и в таком же исходном положении диастолического (давления крови на стенки сосудов в момент, когда сердце наполняется и отдыхает между ударами). Данные показатели были по результатам трех измерений подвергнуты математической обработке и выявлены усредненные показатели в каждой возрастной группе.

\section{Аитературный обзор}

В начале младшего школьного возраста сердечно-сосудистая система претерпевает ряд изменений. Сердце ребенка невелико по объему, не обладает достаточной силой, но достаточно широкий просвет сосудов и относительно больший, чем у взрослых, минутный объем крови (в расчете на килограмм массы тела) обеспечивает достаточное кровоснабжение органов. Однако в отличие от взрослых, достижение необходимого минутного объема обеспечивается у детей в большей степени за счет частоты сердечных сокращений, тем самым компенсируя небольшой ударный объем [6]. Длина артерий возрастает пропорционально росту тела и конечностей $[1,2]$. У детей к окончанию младшего школьного возрас- та, примерно к 10 годам, выявлены процессы снижения возбудимости предсердий, повышение проводимости, удлинение сердечного цикла, систолы и диастолы, а также повышение активности автономного контура регуляции сердечного ритма [5,6]. Следует отметить, что по данным исследований Шарапова А.Н., Безобразова В.Н., Догадкина С.Б., Кмить Г.В., Рублева Л.В. дети младшего школьного возраста, у которых все-таки преобладает влияние симпатической нервной системы на сердечный ритм, характеризуются меньшей продолжительностью сердечного цикла, фазы изометрического сокращения, времени изгнания крови и большая длительность диастолы наряду с увеличением амплитуды зубцов Р, R и T, что также, свидетельствует о менее зрелом и более энергозатратном типе регулирования гомеостаза в ССС $[3,4]$.

\section{Результаты}

В таблице 1 представлена динамика показателей нормального регулярного синусового ритма (ЧСС в покое) и показателя адаптационных возможностей сердечно-сосудистой системы (ЧСС после 30 приседаний).

В соответствии с полученными результатами у девочек в возрасте семи лет наблюдается снижение показателей нормального регулярного синусового ритма (ЧСС

Таблица 1.

Динамика показателей чСС в покое и после 30 приседаний у юных гимнасток

\begin{tabular}{|c|c|c|c|c|c|c|c|c|c|c|c|}
\hline \multirow{3}{*}{$\begin{array}{c}\text { возраст } \\
\text { спортсменок }\end{array}$} & \multirow{3}{*}{$\begin{array}{c}\text { стат. } \\
\text { показатель }\end{array}$} & \multicolumn{3}{|c|}{ ЧСС в покое } & \multicolumn{2}{|c|}{$\begin{array}{c}\text { темп базисного } \\
\text { прироста \% }\end{array}$} & \multicolumn{3}{|c|}{ ЧСС по нагрузки } & \multicolumn{2}{|c|}{$\begin{array}{c}\text { темп базисного } \\
\text { прироста \% }\end{array}$} \\
\hline & & фев. & авг. & янВ. & авг. & янВ. & $\phi е в$. & авг. & янв. & авг. & янв. \\
\hline & & 2020 & 2020 & 2021 & 2020 & 2021 & 2020 & 2020 & 2021 & 2020 & 2021 \\
\hline \multirow{4}{*}{7 лет } & M & 102,50 & 98,40 & 104,55 & \multirow{4}{*}{$\begin{array}{c}-4,00 \\
* *\end{array}$} & \multirow{4}{*}{$\begin{array}{c}2,00 \\
*\end{array}$} & 153,95 & 154,55 & 155,05 & \multirow{4}{*}{0,37} & \multirow{4}{*}{$\begin{array}{c}0,75 \\
*\end{array}$} \\
\hline & $\sigma$ & 3,17 & 20,96 & 2,91 & & & 6,19 & 7,76 & 7,10 & & \\
\hline & $\pm m$ & 0,71 & 4,69 & 0,65 & & & 1,39 & 1,73 & 1,59 & & \\
\hline & V & 3,09 & 21,30 & 2,78 & & & 4,02 & 5,02 & 4,58 & & \\
\hline \multirow{4}{*}{8 лет } & M & 110,90 & 111,80 & 110,85 & \multirow{4}{*}{0,31} & \multirow{4}{*}{$-0,05$} & 144,15 & 146,65 & 149,85 & \multirow{4}{*}{$\begin{array}{c}1,39 \\
*\end{array}$} & \multirow{4}{*}{$\begin{array}{c}4,13 \\
* *\end{array}$} \\
\hline & $\sigma$ & 7,73 & 6,93 & 6,92 & & & 8,00 & 6,01 & 6,92 & & \\
\hline & $\pm m$ & 1,73 & 1,55 & 1,55 & & & 1,79 & 1,34 & 1,55 & & \\
\hline & V & 6,97 & 6,20 & 6,25 & & & 5,55 & 4,10 & 4,62 & & \\
\hline \multirow{4}{*}{9 лет } & M & 109,35 & 105,50 & 102,75 & \multirow{4}{*}{$\begin{array}{c}-3,57 \\
* *\end{array}$} & \multirow{4}{*}{$\begin{array}{l}-6,05 \\
* *\end{array}$} & 134,35 & 129,70 & 129,45 & \multirow{4}{*}{$\begin{array}{c}-3,21 \\
* *\end{array}$} & \multirow{4}{*}{$\begin{array}{r}-3,44 \\
* *\end{array}$} \\
\hline & $\sigma$ & 0,54 & 8,62 & 7,44 & & & 11,61 & 7,60 & 7,39 & & \\
\hline & $\pm m$ & 0,12 & 1,93 & 1,66 & & & 2,60 & 1,70 & 1,65 & & \\
\hline & V & 0,49 & 8,17 & 7,24 & & & 8,64 & 5,86 & 5,71 & & \\
\hline \multirow{4}{*}{10 лет } & M & 103,80 & 107,70 & 106,30 & \multirow{4}{*}{$\begin{array}{c}3,76 \\
* *\end{array}$} & \multirow{4}{*}{$\begin{array}{c}2,41 \\
*\end{array}$} & 150,10 & 145,20 & 141,80 & \multirow{4}{*}{$\begin{array}{l}-2,97 \\
*\end{array}$} & \multirow{4}{*}{$\begin{array}{l}-5,25 \\
* *\end{array}$} \\
\hline & $\sigma$ & 7,30 & 4,32 & 3,47 & & & 9,38 & 3,99 & 3,56 & & \\
\hline & $\pm \mathrm{m}$ & 1,63 & 0,97 & 0,77 & & & 2,10 & 0,89 & 0,80 & & \\
\hline & V & 7,04 & 4,01 & 3,26 & & & 6,25 & 2,75 & 2,51 & & \\
\hline
\end{tabular}


в покое) к августу и наблюдается отрицательное значение в 4 \% темпа базисного прироста данного показателя. В дальнейшем колебание данного показателя стремится к положительному значению - темп базисного прироста к январю составляет 2\%. Следует отметить, что исследование показателя адаптационных возможностей сердечно-сосудистой системы (ЧСС после 30 приседаний) по итогу трех измерений отражает достоверную взаимосвязь я только по отношению к январю 2021 года (темп базисного прироста составляет 0,75 \%).

У девочек в возрасте 8 лет темп базисного прироста нормального регулярного синусового ритма (ЧСС в покое) отражает положительные незначительные сдвиги к августу и имеет не значительную отрицательную тенденцию к январю. Темп базисного прироста показателя адаптационных возможностей сердечно-сосудистой системы (ЧСС после 30 приседаний) к августу и январю увеличивается и составляет 1,39\% и 4,13\% соответственно.

В группе девочек в возрасте 9 лет темп базисного прироста нормального регулярного синусового ритма (ЧСС в покое) демонстрирует отрицательное значение к августу 2020 и к январю 2021 году и составляет - 3,57\% и 6,05\% соответственно. Показатель адаптационных воз- можностей сердечно-сосудистой системы (ЧСС после 30 приседаний) и темп его базисного прироста к августу и январю носит отрицательное значение и составляет $-3,21 \%$ и $-3,44 \%$ соответственно.

У девочек в возрасте 10 лет темп базисного прироста данного показателя составляет 3,76\% к августу и 2,41\% к январю 2021 года. Показатель адаптационных возможностей сердечно-сосудистой системы (ЧСС после 30 приседаний) и темп его базисного прироста к августу и январю носит отрицательное значение и составляет $-2,97 \%$ и $-5,25 \%$ соответственно.

Далее были зафиксированы параметры артериального давления у девочек в каждой из четырех возрастных групп (таблица 2).

Динамика показателей систолического давления, т.е. силы, с которой насыщенная кислородом кровь выталкивается из сердца и расходится по телу (в покое, сидя) у девочек в возрасте в трех возрастных группах - от 7 до 9 лет отражает положительный темп базисного прироста. Однако у девочек в возрасте 10 лет имеет отрицательную тенденцию по отношению к январю, однако достоверность данной тенденции не нашла статистического подтверждения.

Таблица 2.

Динамика показателей систолического и диастолического артериального давления у юных гимнасток

\begin{tabular}{|c|c|c|c|c|c|c|c|c|c|c|c|}
\hline \multirow{3}{*}{$\begin{array}{c}\text { возраст } \\
\text { спортсменок }\end{array}$} & \multirow{3}{*}{$\begin{array}{c}\text { стат. } \\
\text { показатель }\end{array}$} & \multicolumn{3}{|c|}{ САД } & \multicolumn{2}{|c|}{$\begin{array}{c}\text { темп базисного } \\
\text { прироста \% }\end{array}$} & \multicolumn{3}{|c|}{ ДАД } & \multicolumn{2}{|c|}{$\begin{array}{c}\text { темп базисного } \\
\text { прироста \% }\end{array}$} \\
\hline & & фев. & авг. & янВ. & авг. & ЯнВ. & фев. & авг. & янВ. & авг. & янВ. \\
\hline & & 2020 & 2020 & 2021 & 2020 & 2021 & 2020 & 2020 & 2021 & 2020 & 2021 \\
\hline \multirow{4}{*}{7 лет } & $M$ & 104,80 & 104,90 & 109,10 & \multirow{4}{*}{0,10} & \multirow{4}{*}{$\begin{array}{l}4,18 \\
* *\end{array}$} & 61,55 & 65,80 & 72,05 & \multirow{4}{*}{$\begin{array}{c}6,92 \\
* *\end{array}$} & \multirow{4}{*}{$\begin{array}{c}17,47 \\
* *\end{array}$} \\
\hline & $\sigma$ & 3,22 & 3,23 & 1,83 & & & 3,52 & 3,87 & 1,64 & & \\
\hline & $\pm m$ & 0,72 & 0,72 & 0,41 & & & 0,79 & 0,87 & 0,37 & & \\
\hline & V & 3,07 & 3,08 & 1,68 & & & 5,71 & 5,89 & 2,27 & & \\
\hline \multirow{4}{*}{8 лет } & $M$ & 105,50 & 109,95 & 110,16 & \multirow{4}{*}{$\begin{array}{c}4,22 \\
* *\end{array}$} & \multirow{4}{*}{$\begin{array}{c}4,35 \\
* *\end{array}$} & 69,95 & 72,90 & 72,25 & \multirow{4}{*}{$\begin{array}{l}4,37 \\
* *\end{array}$} & \multirow{4}{*}{$\begin{array}{c}3,44 \\
* *\end{array}$} \\
\hline & 0 & 8,36 & 2,84 & 3,05 & & & 2,91 & 2,27 & 3,14 & & \\
\hline & $\pm \mathrm{m}$ & 1,87 & 0,63 & 0,68 & & & 0,65 & 0,51 & 0,70 & & \\
\hline & $\mathrm{V}$ & 7,92 & 2,58 & 2,78 & & & 4,16 & 3,11 & 4,35 & & \\
\hline \multirow{4}{*}{9 лет } & $M$ & 105,00 & 104,90 & 109,10 & \multirow{4}{*}{$-0,09$} & \multirow{4}{*}{$\begin{array}{c}3,99 \\
* *\end{array}$} & 69,35 & 71,25 & 72,45 & \multirow{4}{*}{$\begin{array}{c}2,92 \\
*\end{array}$} & \multirow{4}{*}{$\begin{array}{c}4,66 \\
* *\end{array}$} \\
\hline & 0 & 3,29 & 3,23 & 1,83 & & & 3,54 & 2,65 & 3,46 & & \\
\hline & $\pm m$ & 0,74 & 0,72 & 0,41 & & & 0,79 & 0,59 & 0,77 & & \\
\hline & $\mathrm{V}$ & 3,14 & 3,08 & 1,68 & & & 5,11 & 3,72 & 4,77 & & \\
\hline \multirow{4}{*}{10 лет } & $M$ & 105,05 & 108,10 & 104,75 & \multirow{4}{*}{$\begin{array}{c}2,90 \\
*\end{array}$} & \multirow{4}{*}{$-0,29$} & 68,45 & 68,35 & 66,85 & \multirow{4}{*}{0,22} & \multirow{4}{*}{$-1,90$} \\
\hline & 0 & 5,14 & 4,27 & 5,10 & & & 4,78 & 3,96 & 1,84 & & \\
\hline & $\pm m$ & 1,15 & 0,95 & 1,14 & & & 1,07 & 0,89 & 0,41 & & \\
\hline & $\mathrm{V}$ & 4,89 & 3,95 & 4,87 & & & 6,99 & 5,80 & 2,76 & & \\
\hline
\end{tabular}


Динамика показателей диастолического давления, т.е. давления крови на стенки сосудов в момент, когда сердце наполняется и отдыхает между ударами (в покое, сидя) у девочек в возрасте в трех возрастных группах от 7 до 9 лет отражает положительный темп базисного прироста. Однако у девочек в возрасте 10 лет имеет отрицательную тенденцию по отношению к январю, однако достоверность данной тенденции не нашла статистического подтверждения.

\section{Обсужмение}

Полученные в ходе исследование результаты демонстрируют статистически значимую изменчивость показателей ЧСС и АД у юных спортсменок в возрасте от семи до 10 лет. Процент изменчивости, исследуемых показателей, вероятней всего обусловлен с одной стороны возрастными особенностями развития на данном этапе онтогенеза, а с другой - объемами и интенсивностью тренировочных нагрузок юных спортсменок. Наибольшее статистически значимое увеличение показателя диастолического давления и темпа базисного прироста к январю 2021 года зафиксировано у девочек в возрасте 7 лет и отражает адаптационные сдвиги в сердечно-сосудистой системе на 1 года спортивной подготовки по виду спорта. С возрастом, уже к 10 года сердечно-сосудистая система менее ярко реагируют на воздействие тренировочных нагрузок и диастолическое давление сохраняет относительно стабильную величину на протяжение всех трех обследований.

Частота сердечных сокращений к возрасту 9 лет стабилизируется и имеет тенденцию к отрицательному приросту, что также отражает адаптацию к предлагаемым нагрузкам у спортсменок. Однако следует отметить, что в возрасте 8 лет показатель ЧСС после нагрузки имеют тенденцию к увеличению своего значения. Вероятно, данное обстоятельство обусловлено интенсификацией процесса подготовки и увеличением тренировочных нагрузок по программе спортивной подготовки.

\section{Зак^ючение}

Исследуемые показатели - ЧСС и артериальное давление (САД, ДАД) являются биологическими маркерами состояния сердечно-сосудистой системы и реакции организма юных гимнасток в возрасте от семи до 10 лет на тренировочные нагрузки. Изменения данных показателей обусловлено, как и со стороны естественных физиологических изменений организма в данном возрасте, так и «усиленно» влиянием тренировочных нагрузок. При этом воздействие тренировочных нагрузок по объему и интенсивности в соответствии с ФССП для спортсменок в каждом возрастном периоде имеет тенденцию увеличению своих значений. Данное обстоятельство отражается на показателях нормального регулярного синусового ритма (ЧСС в покое) и адаптационных возможностей сердечно-сосудистой системы (ЧСС после 30 приседаний). Более ярко в раннем возрасте данное обстоятельство также отражается и на показателях артериального давления. Исходя из положений, определенных в результате анализа представленных показателей, возможно заключить, что параметры чСС в покое и после нагрузки, наряду с артериальным давлением являются достоверными биологическими маркерами физиологических изменений состояния организма у юных спортсменок в возрасте от 7 до 10 лет в художественной гимнастике.

\section{ЛИТЕРАТУРА}

1. Бабичев В.Н. Организация и функционирование нейроэндокринной системы//Пробл.эндокр..2013.№1.URL:https://cyberleninka.ru/article/n/organizatsiyai-funktsionirovanie-neyroendokrinnoy-sistemy (дата обращения: 01.08.2020).

2. Баёва Н.А., Погадаева 0.В. Анатомия и физиология детей школьного возраста: Учебное пособие. - Омск: СибГУФК, 2003. - 56 с.

3. Здоровье детей : метод. пособие для студентов мед. ВУЗов / Казан. гос. мед. ун-т М-ва здравоохранения и социал. развития Рос. Федерации, Каф. пропедевтики дет. болезней и фак. педиатрии с курсом дет. болезней лечеб. фак.; [сост.: Р. А. Файзуллина и др.]. - Казань : КГМУ. - 2012 - Ч. 1: Факторы, формирующие здоровье детей. - 2012. - 28 с

4. Коркушко О.В., Чеботарев Д.Ф., Чеботарев Н.Д. Возрастные изменения дыхательной системы при старении и их роль в развитии бронхо-легочной патологии // Укра'шский пульмонолопчний журнал. 2005. № 3. С. 35-41

5. Крысюк 0.Н. Возрастные особенности биоэлектрической активности миокарда и автономной нервной регуляции сердечного ритма у детей 7-11 лет. // Новые исследования. 2008. №16-1. URL: https://cyberleninka.ru/article/n/vozrastnye-osobennosti-bioelektricheskoy-aktivnosti-miokarda-i-avtonomnoynervnoy-regulyatsii-serdechnogo-ritma-u-detey-7-11-let (дата обращения: 17.01.2021).

6. Шлык Н.И. Особенности вариабельности сердечного ритма и гемодинамики у детей и подростков с различным уровнем зрелости регуляторных систем организма /Н.И. Шлык// новые исследования. Альманах. - 2004. - №1,2. - С. 430-431

7. Шувалова Л.С. Динамика показателей физического развития у девочек в возрасте 7 - 10 лет в художественной гимнастике // Современная наука: актуальные проблемы теории и практики. Серия: Гуманитарные науки. -2021. -№02. -С. 129-134 D0I 10.37882/2223-2982.2021.02.39 